\title{
Combined use of GABA and sitagliptin promotes human $\beta$-cell proliferation and reduces apoptosis
}

\author{
Wenjuan Liu', Harry Kevin Lau², Dong Ok Son'2, Tianru Jin 3,4,5, Yehong Yang1, Zhaoyun Zhang', Yiming Li1, \\ Gerald J Prud'homme ${ }^{6}$ and Qinghua Wang1 \\ 1Department of Endocrinology and Metabolism, Huashan Hospital, Fudan University, Shanghai, China \\ 2Division of Endocrinology and Metabolism, The Keenan Research Centre in the Li Ka Shing Knowledge Institute, St. Michael's Hospital, Toronto, \\ Ontario, Canada \\ ${ }^{3}$ Department of Physiology, University of Toronto, Toronto, Ontario, Canada \\ ${ }^{4}$ Division of Advanced Diagnostics, Toronto General Research Institutes, University Health Network, Toronto, Ontario, Canada \\ 5Banting and Best Diabetes Centre, University of Toronto, Toronto, Ontario, Canada \\ ${ }^{6}$ Department of Laboratory Medicine and Pathobiology, Keenan Research Centre for Biomedical Science of St. Michael's Hospital, University of Toronto, \\ Toronto, Ontario, Canada
}

Correspondence should be addressed to G J Prud'homme or Q Wang: gerald.prudhomme@utoronto.ca or Qinghua.Wang@unityhealth.to

\begin{abstract}
$\gamma$-Aminobutyric acid (GABA) and glucagon-like peptide-1 receptor agonist (GLP-1RA) improve rodent $\beta$-cell survival and function. In human $\beta$-cells, GABA exerts stimulatory effects on proliferation and anti-apoptotic effects, whereas GLP-1RA drugs have only limited effects on proliferation. We previously demonstrated that GABA and sitagliptin (Sita), a dipeptidyl peptidase-4 inhibitor which increases endogenous GLP-1 levels, mediated a synergistic $\beta$-cell protective effect in mice islets. However, it remains unclear whether this combination has similar effects on human $\beta$-cell. To address this question, we transplanted a suboptimal mass of human islets into immunodeficient NOD-scidgamma mice with streptozotocin-induced diabetes, and then treated them with GABA, Sita, or both. The oral administration of either GABA or Sita ameliorated blood glucose levels, increased transplanted human $\beta$-cell counts and plasma human insulin levels. Importantly, the combined administration of the drugs generated significantly superior results in all these responses, as compared to the monotherapy with either one of them. The proliferation and/or regeneration, improved by the combination, were demonstrated by increased Ki67+, PDX-1+, or Nkx6.1+ $\beta$-cell numbers. Protection against apoptosis was also significantly improved by the drug combination. The expression level of $\alpha$-Klotho, a protein with protective and stimulatory effects on $\beta$ cells, was also augmented. Our study indicates that combined use of GABA and Sita produced greater therapeutic benefits, which are likely due to an enhancement of $\beta$-cell proliferation and a decrease in apoptosis.
\end{abstract}

(c) 2021 Society for Endocrinology Published by Bioscientifica Ltd. Printed in Great Britain
Key Words
- GABA
- sitagliptin
- human islet
- $\beta$-cell
- type 1 diabetes

Journal of Endocrinology (2021) 248, 133-143 


\section{Introduction}

The decrease in beta cells number could be due to limited proliferation and increased apoptosis, or both, which leads to chronic hyperglycemia as seen in type 1 diabetes (T1D), and at the end stage of type 2 diabetes (T2D) (Pettus et al. 2013, Jin \& Weng 2016). Thus, it is of critical importance to investigate new therapeutic methods that have two actions: to increase human $\beta$-cell proliferation and/or regeneration, and to reduce apoptosis. However, no single therapy has succeeded in making the majority of these diabetic patients reach recommended glycemic control goals (Wood et al. 2013, Griffin et al. 2014). We hypothesized that a combination therapy with existing drugs, and potential novel drugs, could increase the $\beta$-cell mass and provide improved treatments for T1D and T2D subjects.

Glucagon-like peptide-1 (GLP-1) is an incretin hormone released from gastrointestinal L cells in response to food ingestion, and has been currently used for the treatment of T2D (Wang \& Brubaker 2002, Drucker 2013). GLP-1 exerts its biological effects via activation GLP-1 receptor (GLP-1R). GLP-1 binds to GLP-1R activates cAMP-dependent signaling pathway to facilitate insulin secretion in a glucose-dependent manner (Farilla et al. 2003, Drucker 2013). Activation of GLP-1R on the beta cells also initiates cell growth and survival signaling pathways involving PI3K/Akt signaling (Wang \& Brubaker 2002, Drucker 2013). In addition to its insulinotrophic effects, GLP-1 also possesses insulin mimetic effects in insulin-responsive tissues or cells (Tomas \& Habener 2010, Tomas et al. 2015). However, GLP-1 has a short half-life (1-2 min) due to rapid enzymatic degradation by dipeptidyl peptidase-4 (DPP-4) and renal clearance (Deacon 2004). This has led to the development of two categories of novel therapeutic agents for diabetes, known as GLP-1 receptor agonists (GLP-1RA) and dipeptidyl peptidase-4 inhibitors (DPP-4I) (Drucker 2006). Findings by our team and by others have shown that GLP-1-based drugs promote rodent $\beta$-cell proliferation (Wang et al. 2013, Liu et al. 2017); however, they only have limited or marginal effects on human $\beta$-cells (Rother et al. 2009, Tian et al. 2011, Zhao et al. 2014).

$\gamma$-Aminobutyric acid (GABA) was initially identified as a major neurotransmitter in the CNS, but its actions on pancreatic islet cells and immune cells have been described much more recently. In the peripheral endocrine system, GABA plays an important role in the regulation of isletcell function and glucose homeostasis (Xu et al. 2006, Wang et al. 2019). GABA exerts its biological action by the activation of GABA receptors (Wang et al. 2019). We previously demonstrated that GABA could enhance $\beta$-cell proliferation, and reduce $\beta$-cell apoptosis (Soltani et al. 2011, Wan et al. 2015, Ben-Othman et al. 2016). It can also generate anti-inflammatory and immunoregulatory effects, which appear to contribute to the anti-diabetic effects (Soltani et al. 2011, Prud'homme et al. 2013, Wan et al. 2015, Wang et al. 2019). More recently, GABA has also been found to stimulate human $\beta$-cells proliferation under in vivo condition, examined through xenotransplantation, which leads to increased functional $\beta$-cell mass (Tian et al. 2013, Purwana et al. 2014). Moreover, our previous study in a T1D mouse model revealed that the combination of GABA and a DPP-4I (sitagliptin, Sita) was considerably superior to either agent alone at preventing apoptosis, and inducing the replication of $\beta$-cells (Liu et al. 2017). In addition, GABA further increased plasma GLP-1 levels when co-administered with DPP-4I. In vitro, GABA and a GLP-1RA (exendin-4) in combination were found to block cytokine-induced apoptosis, and promote insulin secretion in human islets (Son et al. 2018).

The aforementioned evidence suggested that GABA and DPP-4I could collaborate in promoting human $\beta$-cell proliferation, and/or decreasing apoptosis. However, comparable studies have not been performed with human islets. To test our hypothesis for the existence of a collaborative effect, we transplanted a suboptimal number of human islets into diabetic immunodeficient NOD-scidgamma (NSG) mice followed by oral treatments with GABA, Sita, or both for 10 weeks. Our results showed that either GABA or Sita promoted human $\beta$-cell proliferation and insulin production along with increased $\beta$-cell numbers, while decreasing $\beta$-cell apoptosis. Importantly, the combined administration of these two agents had an additive effect as compared to GABA or Sita monotherapy.

\section{Materials and methods}

\section{Human islet isolation}

Pancreata were obtained from donors and the informed consents were obtained from the donor antemortem. Human islets were isolated by the University Health Network Islet Isolation Program, University of Toronto (No. 14-8321.2) (Negi et al. 2012, Purwana et al. 2014, Batchuluun et al. 2018). The isolation protocol was reviewed and approved by the University Health Network Research Ethics Board committee, and all methods were 
performed in accordance with the relevant guidelines and regulations. After isolation and purification, the human islet morphology was observed, and glucose-stimulated insulin secretion (GSIS) assay was performed to check the secretory function. Donor information was listed in Supplementary Table 1 (see section on supplementary materials given at the end of this article). Islets from all four donors were used in in vitro experiments, whereas islets from the first donor (46 years old male) were used for our in vivo transplantation as well (islet morphology and GSIS results were shown in Supplementary Fig. 1).

\section{Human islet transplantation and animal study}

All experimental protocols were approved by the Institutional Animal Care and Use Committee (IACUC) at St. Michael's Hospital, University of Toronto (ACC817). Male NOD.Cg-Prkdssid Il2rgtm1wil/SzJ (denoted NOD-scid- $\gamma$, NSG) were purchased from Jackson Laboratories. All mice were maintained in a pathogen-free environment and housed in groups of five animals per cage with constant temperature and humidity and $12 \mathrm{~h}$ light: $12 \mathrm{~h}$ darkness cycle. After 1 week of adaptive housing, mice were rendered diabetic with a high-dose of streptozotocin (STZ) injections (on day $0-1 ; 125 \mathrm{mg} / \mathrm{kg}$ for two consecutive days; Sigma-Aldrich) as described previously (Purwana et al. 2014). Mice with blood glucose (BG) $>18 \mathrm{mmol} / \mathrm{L}$ for 2 days were selected for experiments and transplanted with a suboptimal dose of human islets on day 5 (1100 islet equivalents (IEQ)) under the kidney capsule as previously described (Purwana et al. 2014). This leaves a margin to observe whether our treatments improve hyperglycemia in these diabetic mice. Mice were then randomly divided into four groups and each group has nine mice: non-treatment diabetic control group (Ctrl), GABA treatment group (GABA), sitagliptin (Sita) treatment group, and GABA plus Sita group (Fig. 1A). GABA (SigmaAldrich, $6 \mathrm{mg} / \mathrm{mL}$ in drinking water), or Sita (Merck Inc., $0.4 \mathrm{mg} / \mathrm{L}$ in drinking water), or GABA plus Sita were orally administrated started on day 12 and maintained during the treatment course of 10 weeks.

Starting on the day of human islet transplantation, a subtherapeutic dose of subcutaneous insulin (7.5 units/kg body weight; Detemir, Novo Nordisk) was administered daily as a treatment for dehydration owing to high BG to all animals. The dosage of insulin injection was decreased to $3.75 \mathrm{U} / \mathrm{kg}$ body weight from day 63 , and totally omitted 10 days before termination to observe the treatment effects on blood glucose as well as to avoid drug effects on plasma sample bioassay. Ten weeks post-treatment,
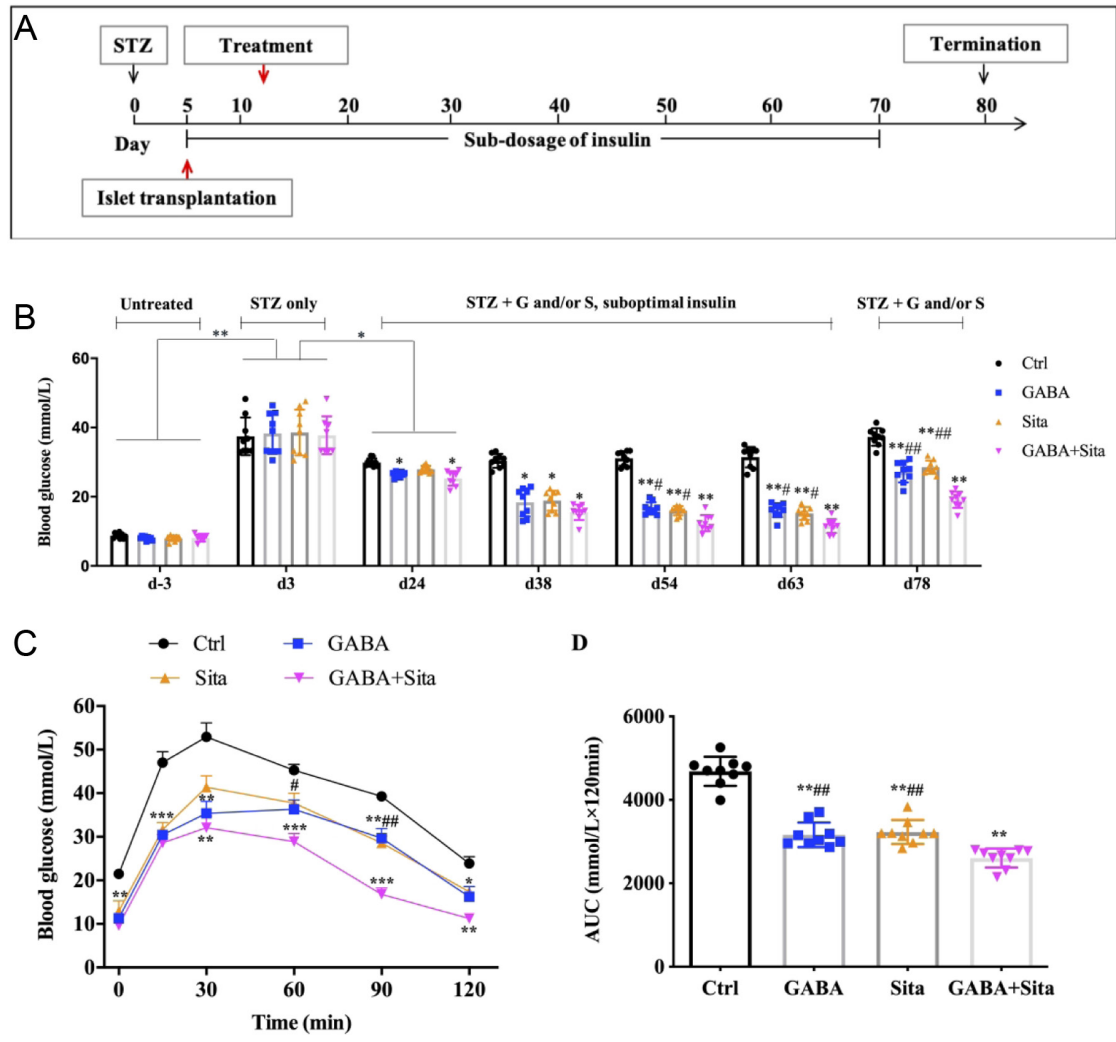

D

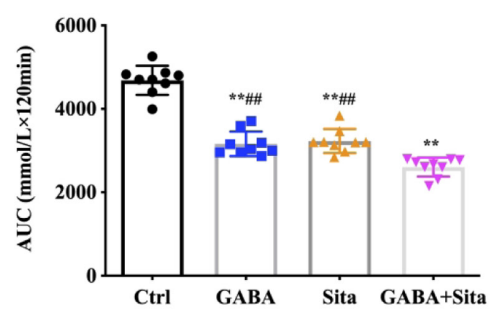

\section{Figure 1}

Combined use of GABA and Sita generates additive effects on improving glucose homeostasis. (A) A chart shows the experimental design. (B) Blood glucose levels were measured weekly in the course of GABA, Sita, or GABA+Sita administration. (C) IPGTT was performed at the end of the treatment course, and area under curve (AUC) is shown (D). Data are mean \pm S.D. and $n=9$ for each of the four groups. $* P<0.05$, $\star \star P<0.01, * \star \star P<0.001$ vs Ctrl (control) group; $\# P<0.05, \# P<0.01$ vs GABA+Sita group. 
mice were killed, and the blood samples were collected for the measurement of plasma human and mouse insulin (ELISA kits, Millipore), and glucagon (glucagon ELISA kit, Millipore) according to manufacturer's instructions.

\section{Blood glucose and intraperitoneal glucose tolerance test (IPGTT)}

Blood glucose was measured through tail vein bleeding with a OneTouch UltraSensitive glucometer (LifeScan Inc., Burnaby, BC, Canada) or glucose assay kit (Abcam). Mice were single-caged and fasted for $6-8 \mathrm{~h}$ prior to the intraperitoneal injection of glucose ( $2 \mathrm{mg} / \mathrm{g}$ body weight). Blood glucose levels were measured at $0,15,30,60$, and $120 \mathrm{~min}$ after the injection and the area under curve (AUC) value was calculated.

\section{Tissue processing and immunostaining analysis}

The graft-containing kidney and mouse pancreas samples were collected without saline perfusion and immediately processed for paraffin embedding and histological analysis as previously described (Purwana et al. 2014). Histological sections $(4 \mathrm{~mm}$ ) were sliced by using a Leica RM2145 rotary microtome. For graft $\beta$ - and $\alpha$-cell counts or pancreatic islet $\beta$ - and $\alpha$-cell mass analysis, insulin and glucagon dual immunofluorescent (IF) or immunohistochemical (IHC) staining were performed (Liu et al. 2017). Proliferative human $\beta$-cells were detected in the kidney graft sections by double IF staining with insulin and Ki67. $\beta$-cell lineage markers, pancreatic and duodenal homeobox-1 (PDX-1) or NK6 homeobox 1 (Nkx6.1) were also detected by dual staining with insulin. Apoptotic human $\beta$-cells were also identified in kidney graft sections with insulin and terminal deoxynucleotidyl transferase dUTP nick end labeling (Tunel) labeling (TMR red, Roche). $\alpha$-Klotho expression by human $\beta$-cells levels was detected dual immunofluorescent staining with insulin. All antibodies used in immunostaining were listed in Supplementary Table 2.

Microscopic images were captured using an Olympus upright BX50 fluorescence microscope (Olympus) or scanned with Zeiss Zxioscan.z1 program. For Ki67/insulin or Tunel/insulin dual staining, results were presented as the percentage of $\mathrm{Ki}^{6} 7^{+}$or Tunel $^{+}$human $\beta$-cell percentage; while for PDX-1/insulin or Nkx6.1/insulin staining, results were expressed as the ratio of PDX-1+ $1^{+}$or Nkx6.1+ human $\beta$-cells to the total $\beta$ - and $\alpha$-cell counts. For these immunostaining analysis, three slides from different layers, usually the interval between two slides was more than $40 \mathrm{~mm}$, were performed. For Ki67 or Tunelcounting, at least 2000 human $\beta$-cell/mouse from each sample were analyzed, and data were calculated based on the results from all slides. For a-Klotho and insulin dual staining quantification, the region of interest (ROI) was traced and then the 'grey level intensity' was analyzed for the relevant channel. We then divided a-Klotho to the corresponding insulin staining to get the ratio for analysis. Imaging and counting were performed by a sophisticated pathological technician in a blinded way.

\section{Statistical analysis}

All statistical analyses were performed using the Prism 6 program for Mac (GraphPad). Data are expressed as mean \pm s.E.M. The significance among different groups was evaluated using one-way ANOVA followed by the Tukey test. Differences were considered statistically significant for $P$ values $<0.05$.

\section{Results}

\section{Combined use of GABA and Sita generates additive effects on improving glucose homeostasis}

The combined effects of GABA and GLP-1 were investigated in diabetic mice induced by STZ injection, and then transplanted with human islets. This STZ injection eliminated nearly all the mouse pancreatic $\beta$-cells, with the residual islets containing mostly $\alpha$-cells, as we reported in our previous publication (Purwana et al. 2014). Following human islet transplantation, we could then detect human insulin in the plasma, which contributed to glucose homeostasis (see subsequently).

Our experimental design is summarized in Fig. 1A. Three days after STZ injection, the blood glucose (BG) levels reached $37.57 \pm 1.12 \mathrm{mmol} / \mathrm{L}$, which was decreased to $26.18 \pm 1.37 \mathrm{mmol} / \mathrm{L}$ one week after human islet transplantation. Starting on the day of human islet transplantation, a subtherapeutic dose of subcutaneous insulin was administered daily to all mice to prevent dehydration owing to high BG. We then started to treat the recipient mice with GABA $(6 \mathrm{mg} / \mathrm{mL})$, Sita $(0.4 \mathrm{mg} / \mathrm{mL})$, or GABA plus Sita, administered through the drinking water for 10 weeks. Though lower than the peak level before islet transplantation, the BG levels in the control (Ctrl) group slowly increased over time (Fig. 1B and Supplementary Fig. 2A). However, this tendency was reversed in the GABA, Sita, or GABA plus Sita treatment 
groups. Two weeks after the treatment (day 24), GABA and GABA+Sita groups showed significantly lower BG levels when compared with Ctrl group. Moreover, at 5 weeks after treatment and thereafter, mice from the GABA+Sita group showed lower blood glucose levels when compared to those that received a monotherapy. In order to eliminate the effects of exogenous insulin on the BG levels, we decreased insulin dosage to half post day 63 and completely stopped insulin injections post day 70 . The BG levels in these treated groups slightly increased after we changed the insulin dosage, which gave us a better opportunity to observe the difference between the combined therapy group and the single drug-treated ones. This serial BG testing demonstrated that combined therapy had a superior effect on lowering glucose levels than monotherapies (Fig. 1B and Supplementary Fig. 2A). Regarding the body weight, no significant difference was observed between groups (Supplementary Fig. 2B).

To test whether this combined therapy led to an improved glucose challenge response, IPGTT was performed at the end of the treating course. The mice administrated with GABA or Sita monotherapy showed improved glucose tolerance after 10 weeks of treatment (33.6 and $29.8 \%$ reduction in AUC, respectively), compared with non-treated diabetic mice (Fig. 1C and D). Moreover, mice receiving GABA and Sita in combination exhibited further improvement in glucose disposal ability (44.3\% reduction in AUC) compared with Ctrl group, as well as mice treated with either drug alone.

\section{Additive effects of GABA and Sita on increasing $\beta$-cell counts while decreasing $\alpha$-cell counts in transplanted human islet grafts}

After exposure to different treatments for 10 weeks, transplanted human grafts were collected, and insulin ${ }^{+}$ and glucagon ${ }^{+}$endocrine cell counts were calculated based on the immunofluorescent staining (Fig. 1A). The $\alpha$ - (or $\beta$-) cell percentage was calculated by dividing $\alpha$ (or $\beta$-) cell number to total $(\alpha+\beta)$ cell counts (Fig. $2 \mathrm{~B}$ and Supplementary Fig. 3). The analysis indicated that $\alpha$-cell $\%$ was decreased by either monotherapy (39.0 and 39.9\% in GABA or Sita treated group respectively), while this ratio was down to $29.4 \%$ in GABA+Sita group (Fig. 2B). Vice versa, our results showed a 1.41-, 1.38-, and 1.63fold increase in the $\beta$-cell counts in mice receiving GABA, Sita, and GABA+Sita, respectively (Fig. 2B). Moreover, histomorphological observations revealed a different insulin staining pattern between groups. In mice that did not receive any given treatment, some cells were partially

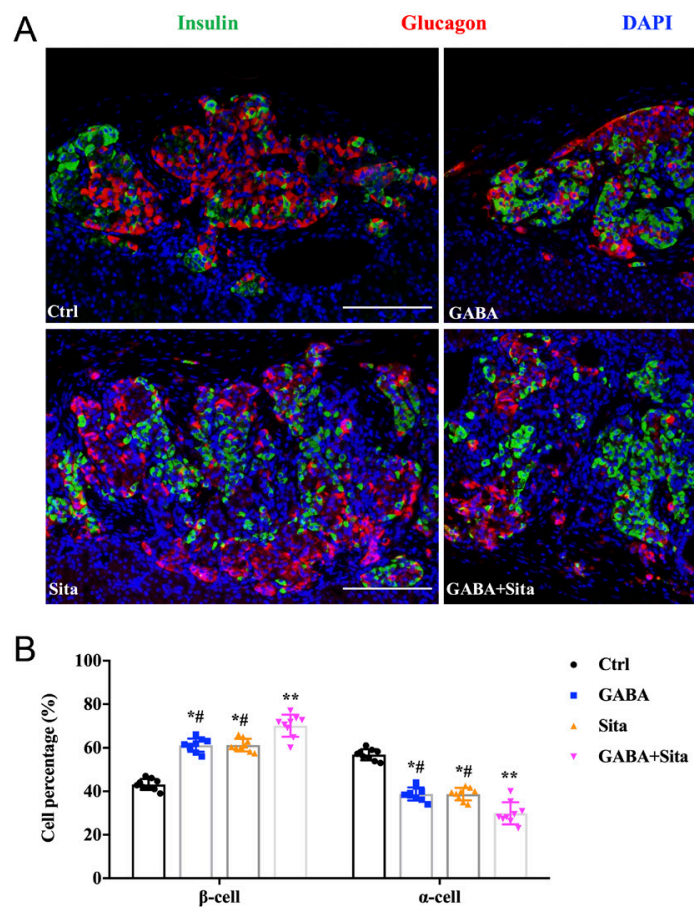

C
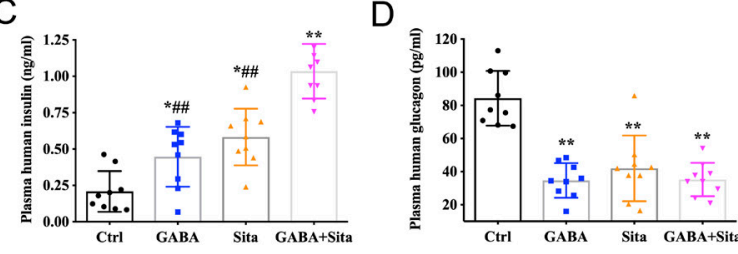

Figure 2

Additive effects of GABA and Sita on increasing $\beta$-cell counts while decreasing $\alpha$-cell counts in transplanted human islet grafts. (A) Representative immunofluorescent images of islet grafts stained with insulin (green), glucagon (red), and DAPI (blue). Scale bars are $100 \mathrm{~mm}$. (B) Quantitative immunofluorescent analyses were performed and demonstrated that combined use of GABA and Sita generated additive effects on increasing $\beta$-cell ratio while decreasing $\alpha$-cell ratio. Circulating human insulin (C) and glucagon (D) levels were measured by specific ELISA kits. Data are mean \pm S.D. and $n=9$ for each of the four groups. ${ }^{\star} P<0.05,{ }^{*} P<0.01$ vs Ctrl group. ${ }^{\#} P<0.01$ vs GABA+Sita group.

stained with insulin, resulting in a faint and blurred staining pattern (Fig. 2A). However, this phenomenon was not observed in the treated groups, which suggested that either GABA or Sita exerted protective effects on human $\beta$-cells.

We have also examined circulating insulin and glucagon levels in the recipient mice. By using a human insulin-specific ELISA kit, we found that compared to untreated mice the administration of GABA or Sita significantly increased plasma human insulin levels while plasma human glucagon levels decreased (Fig. 2C and D). Notably, an additive effect on the elevation of plasma insulin levels, but not on the depression of plasma 

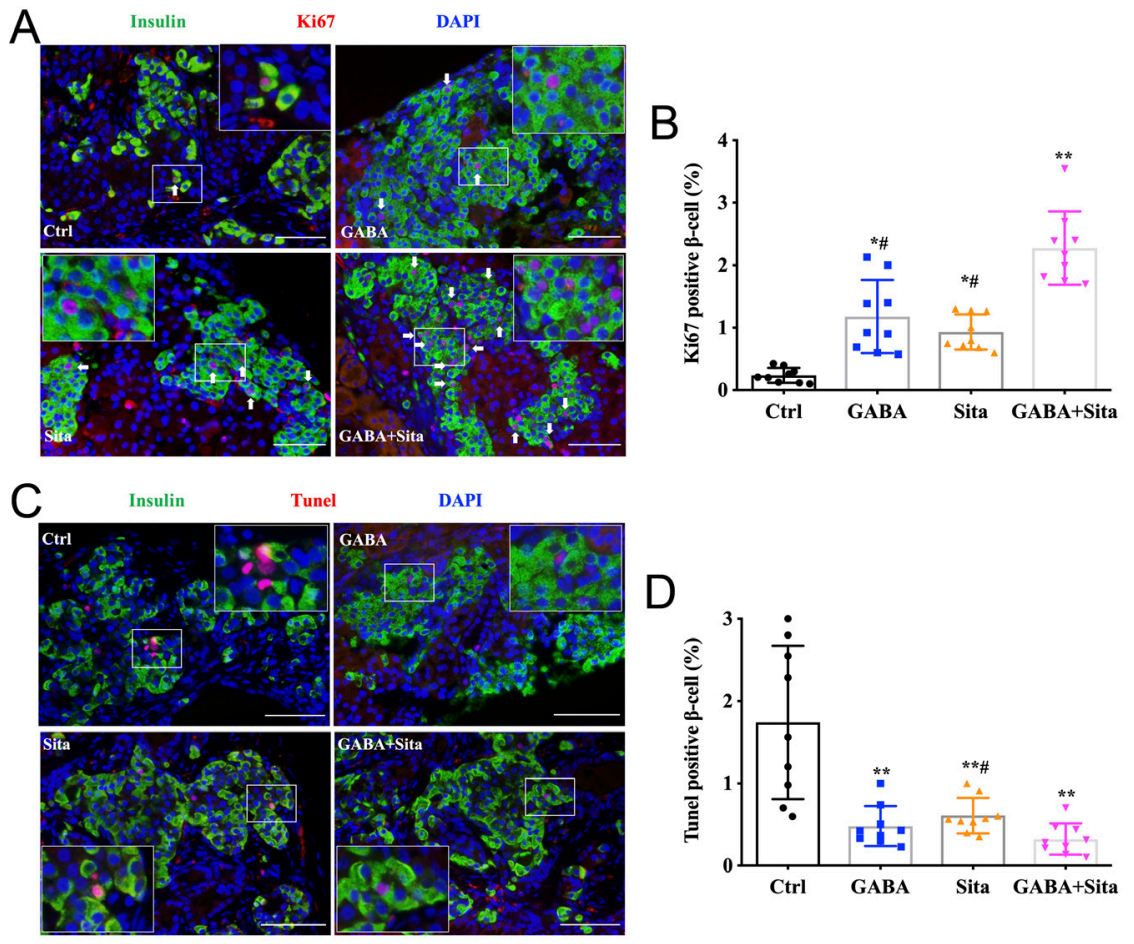

glucagon levels, was observed with the combined therapy (Fig. 3C and D). In addition, we confirmed that no difference was observed between groups regarding mouse pancreatic $\beta$ - and $\alpha$-cell mass, as well as the mouse plasma insulin levels (Supplementary Fig. 4). It is noted that due to the destruction of mouse islet $\beta$-cells by STZ injections, the remaining islet residuals were less than $5-10 \%$ of those before STZ injections. The circulation mouse insulin levels were at relevant very low levels.

\section{Combined use of GABA and Sita generates additive effects on increasing human $\beta$-cell proliferation and/or regeneration, while decreasing human $\beta$-cell apoptosis}

The immunofluorescent analysis showed that either GABA or Sita induced human $\beta$-cell replication in the islet grafts, as demonstrated by an increased number of Ki67+ $\beta$-cells (Fig. 3A and B). Moreover, compared to the 4.4- and 3.6folds improvement of human $\beta$-cell proliferation rate in GABA- and Sita-treated groups vs the control group, the combined therapy group showed an increase of almost 9.1 times (Fig. 3B).

As shown in Fig. 3C, all three treatments significantly reduced $\beta$-cell apoptosis in the human islet grafts in the recipient mice, as determined by insulin-Tunel double staining. This demonstrated the protective effects of GABA and Sita in human islet $\beta$-cells under in vivo conditions.

\section{Figure 3}

Combined use of GABA and Sita generates additive effects on increasing human $\beta$-cell proliferation, while decreasing human $\beta$-cell apoptosis. Representative immunofluorescence images of human islet grafts, showing insulin ${ }^{+}$ (green) and $\mathrm{Ki}^{+} 7^{+}$(red, A, white arrows) or Tunel ${ }^{+}$ (red, C) cells in the four groups of mice. Scale bars are $40 \mathrm{~mm}$. (B) Calculation of percent for Ki67+ $\beta$-cell in four groups. (D) The percent for Tunel ${ }^{+}$ $\beta$-cell in the four groups of mice. Data are mean \pm S.D. and $n=9$ for each of the four groups. $\star P<0.05, * * P<0.01$ vs Ctrl group. $\# P<0.05$ vs GABA+Sita group.
Though this did not reach statistical significance between the combined therapy group and GABA alone, the GABA plus Sita combination tended to generate stronger protection against apoptosis (Fig. 3D). Our previous in vitro data demonstrated that combination of GABA and a GLP-1 receptor agonist exerted additive effects on human $\beta$-cell survival and function, and this was associated with increased expression of $\alpha$-Klotho (Prud'homme et al. 2017, Son et al. 2018). $\alpha$-Klotho has been shown to exert GABAlike effects on $\beta$-cells, for example, protects $\beta$-cell from apoptosis and stimulates the insulin secretion. Here, we analyzed $\alpha$-Klotho expression, and found that combined administration of GABA and Sita generated additive effects on increasing its expression in human islet $\beta$-cells (Supplementary Fig. 5).

We further stained the human islet grafts with insulin and PDX-1 or Nkx6.1, two key $\beta$-cell developmental linage markers (Baeyens et al. 2018), to verify the effects of our treatments on preserving $\beta$-cell counts as well as cell differentiation. Consistent with the aforementioned protective effects, GABA or Sita single treatment significantly increased the number of PDX-1+ insulin ${ }^{+}$ (Fig. 4A, B and Supplementary Table 3) and NKX6.1+ insulin ${ }^{+}$(Fig. 4C, D and Supplementary Table 3) cell counts as compared to the control group, while combined therapy increased these counts even further. Of note, we also observed a number of PDX-1+ insulin- and NKX6.1+ insulin- cells in non-treated mice, which were rare in the 


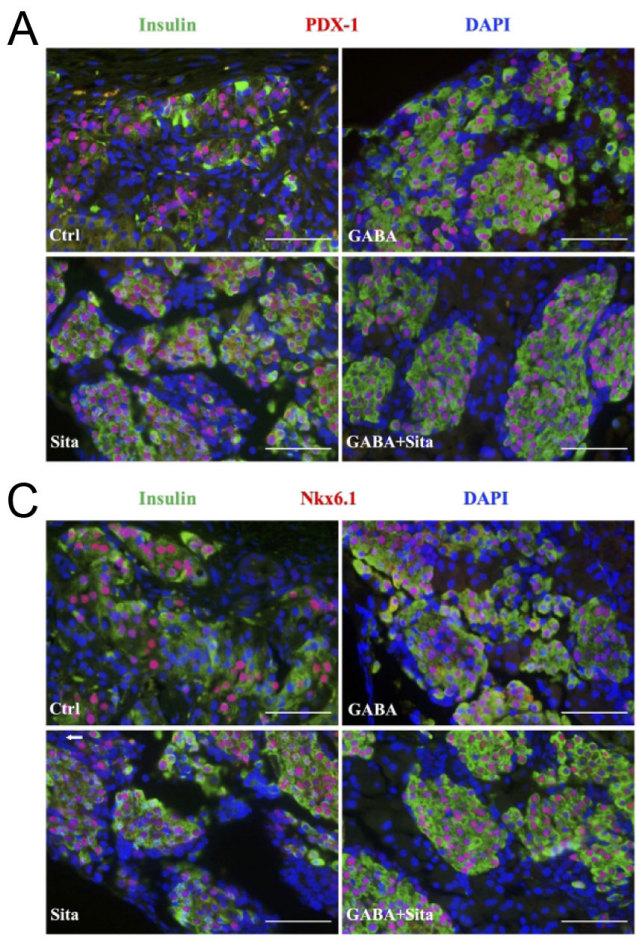

\section{D}

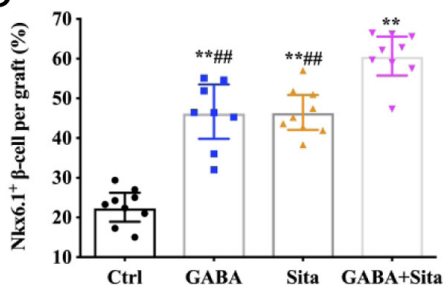

\section{Figure 4}

Combined use of GABA and Sita generates additive effects on increasing human $\beta$-cell regeneration. Representative

immunofluorescence images of human islet grafts, showing insulin ${ }^{+}$(green) and PDX-1+ (red, A) or Nkx6.1 $1^{+}$(red, C) cells in the four groups of mice. Scale bars are $40 \mathrm{~mm}$. (B) Calculation of percent for PDX-1+ $\beta$-cell in four groups. (D) The percent for $\mathrm{Nkx6.1+} \beta$-cell in the four groups of mice. Data are mean \pm S.D. and $n=9$ for each of the four groups. $* \star P<0.01$ vs Ctrl group; $\# P<0.05, \# P<0.01$ vs GABA+Sita group, $n=8-10$ for each group of mice. other three groups. These results suggested that GABA and Sita treatment is able to maintain the $\beta$-cell phenotype (e.g. insulin expression).

\section{Discussion}

Several approaches have been developed to induce islet $\beta$-cell regeneration and increase the $\beta$-cell mass in rodents, but very few of these therapies have had similar effects on human $\beta$-cells. Although in the past human islet $\beta$-cells were defined as terminally differentiated cells with limited proliferative capacity (Baeyens et al. 2018), recent studies have supported that human islet $\beta$-cells still have proliferative plasticity in the case of increased metabolic demands.

In past studies, GABA was identified as an agent that increases human $\beta$-cell proliferation in vitro and in vivo (Tian et al. 2013, Purwana et al. 2014). In vivo studies were performed by transplanting human islets into immunodeficient mice. In these investigations, GABA also exerted anti-apoptotic effects on $\beta$-cells. As we have recently reviewed (Wang et al. 2019), GABA therapy increases human $\beta$-cell proliferation by two- to four-fold. However, since the basal rate of $\beta$-cell proliferation is low $(\leq 0.5 \%)$, the number of proliferating cells induced by the treatment remains relatively small. In contrast, studies regarding the effects of GLP-1-based drugs on promoting human $\beta$-cell proliferation are not consistent (Rother et al. 2009, Tian et al. 2011, Zhao et al. 2014). Interestingly, GLP-1-based drugs were reported to induce human $\beta$-cell replication in an age-dependent manner (Tian et al. 2011, Zhao et al. 2014, Dai et al. 2017). GLP-1 could stimulate human $\beta$-cell proliferation in young patients or patients that received islet transplantations from young donors. Thus, we hypothesized that the combination of GABA with a drug that increases incretin levels, especially GLP-1, might improve the replication rate. This was the case in mice (Liu et al. 2017), where we combined GABA with a DPP-4I (Sita), but the effects on human $\beta$-cells were unknown. In this study we show that GABA and a DPP-4I (Sita) cooperate in an additive way, to boost the human $\beta$-cell replication rate and increase the $\beta$-cell counts.

We induced diabetes in NSG mice by STZ injection, and performed suboptimal human islet transplantation. STZ injection resulted in the destruction of most of the mouse islet $\beta$-cells, the remaining very few islet residues produced very low levels of rodent insulin in the circulation, as demonstrated by the $\beta$-cell counts and plasma mouse insulin measurement. This allowed us to examine any potential improvements in human insulin secretion, glucose homeostasis, and islet cell counts ( $\beta$ - and $\alpha$-cells) in the human islet-xenografted diabetic mice. The mice received insulin supplementation in the early phase of the experiments to control hyperglycemia, which was later reduced and then stopped completely. 
Therapy with either drug alone had a stimulatory effect on $\beta$-cell proliferation (measured by Ki67 staining), and a protective effect against apoptosis (measured by Tunel assay). This was accompanied by increased $\beta$-cell numbers and human insulin levels, as well as improved glucose homeostasis. Concurrently, serum glucagon serum levels were depressed. However, the combined treatment was significantly superior in increasing proliferation (doubled the rates compared to the monotherapies), $\beta$-cell counts, insulin levels, and decreasing apoptosis. These results support our hypothesis that human $\beta$-cell function can be improved through an oral therapeutic intervention. Since the endogenous murine mouse $\beta$-cells were nearly eliminated by high dose STZ injection, the improved glucose disposal ability observed in these recipient mice was due to the enhanced human $\beta$-cell counts and/or function.

Pancreatic duodenal homeobox (PDX-1) and NK6 homeobox 1 (Nkx6.1) are two widely studied transcription factors that regulate pancreatic ontogeny and fetal $\beta$-cell development (Baeyens et al. 2018). In particular, PDX-1, also known as insulin promoter factor, is necessary for $\beta$-cell maturation; and Nkx6.1 is responsible for maintaining the functional and molecular features of mature $\beta$-cells (Taylor et al. 2013). Expression of these two factors is maintained in mature $\beta$-cells and is known to affect glucose-induced insulin secretion and $\beta$-cell survival (Moibi et al. 2007). By dual staining with insulin, we found that both GABA and Sita increased PDX-1 or Nkx6.1 positive $\beta$-cells, but combined therapy increasing these cells the most. This might partially explain the increased $\beta$-cell counts in these treated groups, as well as the amelioration in glucose tolerance. In addition, the combination increased insulin secretion by human $\beta$-cells, supporting the current in vivo findings.

Reduced apoptosis is an important aspect of this therapy. The apoptotic human $\beta$-cell ratio, calculated by the percentage of Tunel $^{+} \beta$-cell, was approximately $1.5 \%$ in non-treated mice. However, this was decreased to approximately $0.5 \%$ in the single treatment groups, and $0.3 \%$ in the combined one. In a previous in vitro study, to investigate the mechanism by which combined treatment improves protection, we treated human islets with proinflammatory cytokines (IL-1 $\beta$, TNF- $\alpha$, and IFN- $\gamma$ ) (Son et al. 2018). Using flow cytometry analysis and western blotting, we demonstrated that the combination of GABA and a GLP-1RA (exendin-4) coactively reduced cytokineinduced apoptosis in human islet $\beta$-cells. Our current in vivo finding of depressed $\beta$-cell apoptosis is in accord with the previous in vitro work. Notably, in vitro, the GABA/ incretin combination increased Akt pathway signaling, which has been linked to increased $\beta$-cell proliferation and survival (Son et al. 2018). There was increased sirtuin-1 (SIRT1) and $\alpha$-Klotho expression, which both appear to exert protective effects on $\beta$-cells (Prud'homme et al. 2014, 2017).

Of note, $\alpha$-Klotho consists of a single-pass membrane protein of 1012 amino acids $(130 \mathrm{kDa})$ with a very short intracytoplasmic segment (10 amino acids). On the membrane, it acts as a coreceptor for fibroblast growth factor 23. The extracellular portion can be cleaved by membrane proteases, and this soluble Klotho form (SKlotho) is released into body fluids where it acts as an endocrine hormone with many functions. $\alpha$-Klotho has major protective effects on $\beta$-cells in rodent models of both T1D and T2D (Lin \& Sun 2015a,b). It appears to protect against apoptosis at least in part through the blockade of NF-кB activation (Buendia et al. 2015, Prud'homme et al. 2017). In human diabetic subjects, $\alpha$-Klotho is depleted in the islets (Lin \& Sun 2015a); and depressed in the serum as observed in T1D (Keles et al. 2016) and T2D (Nie et al. 2017). In diabetic mice (STZ-induced diabetes) GABA markedly increased circulating levels of $\alpha$-Klotho, as well as pancreatic $\beta$-cell expression of this protein (Prud'homme et al. 2017). In view of these findings, we hypothesize that the increased expression of $\alpha$-Klotho, as induced here by the drug combination, contributes to the improved therapeutic response and this merits further investigation.

When analyzing transplanted islet-cell numbers, we observed the interesting phenomenon that insulin staining patterns were different between non-treated and treated mice. Specifically, in some insulin expressing areas the staining was faint, which means that these $\beta$-cells partially lost insulin granules. We speculate that this represents $\beta$-cell dedifferentiation. Some investigators have proposed that $\beta$-cell dedifferentiation is a crucial pathophysiological process underlying the loss of $\beta$-cell mass (Gershengorn et al. 2004, Weinberg et al. 2007, Talchai et al. 2012). Under metabolic or environmental stress, $\beta$-cell dedifferentiated to progenitor-like cells, which no longer contributed to insulin production (Accili et al. 2010).

In control group mice (without GABA or Sita treatment), we saw a number of $\mathrm{PDX}^{-1^{+}}$insulin ${ }^{-}$and Nkx6.1+insulin- cells, whereas these cells were rare in the other three groups. However, in the absence of human $\beta$-cell-specific lineage tracing, we are not able to determine whether dedifferentiation or potential re-differentiation is occurring. Thus, the possibility of these events occurring in our model is of interest, but requires further investigation. 
The proliferative and anti-apoptotic effects of combined application of GABA and GLP-1-based drugs could benefit diabetic patients who have received islet transplantation. Currently, the efficacy of islet transplantation is hampered by considerable loss of islet cells (immediately and chronically), immune rejection and the adverse effects of the immunosuppressive therapy (Gamble et al. 2018). We previously demonstrated, in ex vivo experiments, that immunosuppressive drugs (rapamycin, tacrolimus, and mycophenolate mofetil) are toxic to $\beta$-cells and reduce their survival, whereas GABA protects against these negative effects (Prud'homme et al. 2013). Furthermore, GABA exerted immunosuppressive effects on its own. Thus, the combination of GABA and Sita (or a GLP-1RA agonist) might ameliorate $\beta$-cell protection against injury, as well as stimulate $\beta$-cell replication. These combined effects have the potential of maintaining and increasing the transplanted $\beta$-cell numbers.

We realized that the human islets we used in our transplantation experiments were obtained from the same donor, which is an obvious limitation. We thank you very much for your understanding and discussion with the editor in chief, in view of the current COVID-19 epidemic situation, it appears not feasible to obtain islets from more donors within a reasonable time. In the revised edition, we have pointed out this limitation and have been very cautious in interpreting the results. In the revised edition, we also emphasized that other factors, such as donor's age, gender and islet preparation quality, may affect the outcome of transplantation. Further comprehensive studies are needed to solve these problems

In this human islet transplantation project, we used the islets from one donor (46 years old male with a BMI index of $26 \mathrm{~kg} / \mathrm{m}^{2}$ ). The results demonstrate a significant amelioration of human islet xenotransplantation. It is noted that, several factors might affect the outcome of transplantation, such as donor's age and sex, the quality of the islet preparation, and other factors. While the use of one donor in our work provided uniformity of the islets in the different groups of mice examined, the limited sample size is an obvious limitation of our study, and further investigations are required to address these questions.

In conclusion, our study indicates that combined oral application of GABA and Sita provides better protection of human $\beta$-cells, as compared to one of the monotherapies. This leads to superior effects on metabolic profiles. Since there is no single treatment that could help to prevent or even reverse T1D, our observations suggest that a completely oral drug therapy is feasible in treating these patients, as well as those in the end stage of T2D which manifested as severe $\beta$-cell dysfunction. Further investigations are warranted to analyze the efficacy of GABA and Sita combination therapy for the treatment of diabetes.

\section{Supplementary materials}

This is linked to the online version of the paper at https://doi.org/10.1530/ JOE-20-0315.

\section{Declaration of interest}

Q W holds US Patent 60/595689 regarding GLP-1 fusion construct for treating diabetes; Q W also holds a US Patent 61/138, 957 regarding GABA for the treatment of type 1 diabetes. All the other authors have no potential conflicts of interest to report.

\section{Funding}

This study has been supported by an operating grant from National Natural Science Foundation of China (81570518, 81630020, and 81800751), Juvenile Diabetes Research Foundation (JDRF, 2-SRA-2017-64-G-R to G P, Q W, and T J; and 2-SRA-2015-64 to Q W, G P and T J), and Canadian Diabetes Association (OG-3-13-4066 to Q W).

\section{Author contribution statement}

All authors have contributed significantly and in keeping with the latest guidelines of the International Committee of Medical Journal Editors. Q W and G P contributed to the conception and design of the study. W L contributed to performing the major body of the experiments. $\mathrm{H} L$ and D S helped to perform and analyze the data. T J provided reagents and technique advice. Q W, G P, and W L contributed to writing manuscript. $Y$ $Y, Z Z$, and $Y L$ helped to revise the manuscript. All authors reviewed and approved the content of this manuscript.

\section{References}

Accili D, Ahren B, Boitard C, Cerasi E, Henquin JC \& Seino S 2010 What ails the beta-cell? Diabetes, Obesity and Metabolism 12 (Supplement 2) 1-3. (https://doi.org/10.1111/j.1463-1326.2010.01296.x)

Baeyens L, Lemper M, Staels W, De Groef S, De Leu N, Heremans Y, German MS \& Heimberg H 2018 (Re)generating human beta cells: status, pitfalls, and perspectives. Physiological Reviews 98 1143-1167. (https://doi.org/10.1152/physrev.00034.2016)

Batchuluun B, Al Rijjal D, Prentice KJ, Eversley JA, Burdett E, Mohan H, Bhattacharjee A, Gunderson EP, Liu Y \& Wheeler MB 2018 Elevated medium-chain acylcarnitines are associated with gestational diabetes mellitus and early progression to type 2 diabetes and induce pancreatic beta-cell dysfunction. Diabetes 67 885-897. (https://doi. org/10.2337/db17-1150)

Ben-Othman N, Vieira A, Courtney M, Record F, Gjernes E, Avolio F, Hadzic B, Druelle N, Napolitano T, Navarro-Sanz S, et al. 2017 Longterm GABA administration induces alpha cell-mediated beta-like cell neogenesis. Cell 168 73.e11-85.e11. (https://doi.org/10.1016/j. cell.2016.11.002)

Buendia P, Carracedo J, Soriano S, Madueno JA, Ortiz A, Martin-Malo A, Aljama P \& Ramirez R 2015 Klotho prevents NFkappaB translocation and protects endothelial cell from senescence induced by uremia. Journals of Gerontology: Series A, Biological Sciences and Medical Sciences 70 1198-1209. (https://doi.org/10.1093/gerona/glu170) 
Dai C, Hang Y, Shostak A, Poffenberger G, Hart N, Prasad N, Phillips N, Levy SE, Greiner DL, Shultz LD, et al. 2017 Age-dependent human beta cell proliferation induced by glucagon-like peptide 1 and calcineurin signaling. Journal of Clinical Investigation 127 3835-3844. (https://doi.org/10.1172/JCI91761)

Deacon CF 2004 Circulation and degradation of GIP and GLP1. Hormone and Metabolic Research 36 761-765. (https://doi. org/10.1055/s-2004-826160)

Drucker DJ 2006 The biology of incretin hormones. Cell Metabolism 3 153-165. (https://doi.org/10.1016/j.cmet.2006.01.004)

Drucker DJ 2013 Incretin action in the pancreas: potential promise, possible perils, and pathological pitfalls. Diabetes $623316-3323$. (https://doi.org/10.2337/db13-0822)

Farilla L, Bulotta A, Hirshberg B, Li Calzi S, Khoury N, Noushmehr H, Bertolotto C, Di Mario U, Harlan DM \& Perfetti R 2003 Glucagon-like peptide 1 inhibits cell apoptosis and improves glucose responsiveness of freshly isolated human islets. Endocrinology 144 5149-5158. (https://doi.org/10.1210/en.2003-0323)

Gamble A, Pepper AR, Bruni A \& Shapiro AMJ 2018 The journey of islet cell transplantation and future development. Islets 10 80-94. (https:// doi.org/10.1080/19382014.2018.1428511)

Gershengorn MC, Hardikar AA, Wei C, Geras-Raaka E, Marcus-Samuels B \& Raaka BM 2004 Epithelial-to-mesenchymal transition generates proliferative human islet precursor cells. Science 306 2261-2264. (https://doi.org/10.1126/science.1101968)

Griffin KJ, Thompson PA, Gottschalk M, Kyllo JH \& Rabinovitch A 2014 Combination therapy with sitagliptin and lansoprazole in patients with recent-onset type 1 diabetes (REPAIR-T1D): 12-month results of a multicentre, randomised, placebo-controlled, phase 2 trial. Lancet: Diabetes and Endocrinology 2 710-718. (https://doi.org/10.1016/S22138587(14)70115-9)

Jin T \& Weng J 2016 Hepatic functions of GLP-1 and its based drugs: current disputes and perspectives. American Journal of Physiology: Endocrinology and Metabolism 311 E620-E627. (https://doi. org/10.1152/ajpendo.00069.2016)

Keles N, Dogan B, Kalcik M, Caliskan M, Keles NN, Aksu F, Bulut M, Kostek O, Isbilen B, Yilmaz Y, et al. 2016 Is serum klotho protective against atherosclerosis in patients with type 1 diabetes mellitus? Journal of Diabetes and its Complications 30 126-132. (https://doi. org/10.1016/j.jdiacomp.2015.09.013)

Lin Y \& Sun Z 2015a Antiaging gene klotho attenuates pancreatic betacell apoptosis in type 1 diabetes. Diabetes 64 4298-4311. (https://doi. $\operatorname{org} / 10.2337 / \mathrm{db} 15-0066)$

Lin Y \& Sun Z $2015 b$ In vivo pancreatic beta-cell-specific expression of antiaging gene klotho: a novel approach for preserving beta-cells in type 2 diabetes. Diabetes 64 1444-1458. (https://doi.org/10.2337/ db14-0632)

Liu W, Son DO, Lau HK, Zhou Y, Prud'homme GJ, Jin T \& Wang Q 2017 Combined oral administration of GABA and DPP-4 inhibitor prevents beta cell damage and promotes beta cell regeneration in mice. Frontiers in Pharmacology 8 362. (https://doi.org/10.3389/fphar.2017.00362)

Moibi JA, Gupta D, Jetton TL, Peshavaria M, Desai R \& Leahy JL 2007 Peroxisome proliferator-activated receptor-gamma regulates expression of PDX-1 and NKX6.1 in INS-1 cells. Diabetes 56 88-95. (https://doi.org/10.2337/db06-0948)

Negi S, Jetha A, Aikin R, Hasilo C, Sladek R \& Paraskevas S 2012 Analysis of beta-cell gene expression reveals inflammatory signaling and evidence of dedifferentiation following human islet isolation and culture. PLoS ONE 7 e30415. (https://doi.org/10.1371/journal.pone.0030415)

Nie F, Wu D, Du H, Yang X, Yang M, Pang X \& Xu Y 2017 Serum klotho protein levels and their correlations with the progression of type 2 diabetes mellitus. Journal of Diabetes and its Complications 31 594-598. (https://doi.org/10.1016/j.jdiacomp.2016.11.008)

Pettus J, Hirsch I \& Edelman S 2013 GLP-1 agonists in type 1 diabetes. Clinical Immunology 149 317-323. (https://doi.org/10.1016/j. clim.2013.04.006)
Prud'homme GJ, Glinka Y, Hasilo C, Paraskevas S, Li X \& Wang Q 2013 GABA protects human islet cells against the deleterious effects of immunosuppressive drugs and exerts immunoinhibitory effects alone. Transplantation 96 616-623. (https://doi.org/10.1097/ TP.0b013e31829c24be)

Prud'homme GJ, Glinka Y, Udovyk O, Hasilo C, Paraskevas S \& Wang Q 2014 GABA protects pancreatic beta cells against apoptosis by increasing SIRT1 expression and activity. Biochemical and Biophysical Research Communications 452 649-654. (https://doi.org/10.1016/j. bbrc.2014.08.135)

Prud'homme GJ, Glinka Y, Kurt M, Liu W \& Wang Q 2017 The anti-aging protein Klotho is induced by GABA therapy and exerts protective and stimulatory effects on pancreatic beta cells. Biochemical and Biophysical Research Communications 493 1542-1547. (https://doi. org/10.1016/j.bbrc.2017.10.029)

Purwana I, Zheng J, Li X, Deurloo M, Son DO, Zhang Z, Liang C, Shen E, Tadkase A, Feng ZP, et al. 2014 GABA promotes human beta-cell proliferation and modulates glucose homeostasis. Diabetes $\mathbf{6 3}$ 4197-4205. (https://doi.org/10.2337/db14-0153)

Rother KI, Spain LM, Wesley RA, Digon BJ, 3rd, Baron A, Chen K, Nelson P, Dosch HM, Palmer JP, Brooks-Worrell B, et al. 2009 Effects of exenatide alone and in combination with daclizumab on beta-cell function in long-standing type 1 diabetes. Diabetes Care 32 2251-2257. (https://doi.org/10.2337/dc09-0773)

Soltani N, Qiu H, Aleksic M, Glinka Y, Zhao F, Liu R, Li Y, Zhang N, Chakrabarti R, Ng T, et al. 2011 GABA exerts protective and regenerative effects on islet beta cells and reverses diabetes. PNAS 108 11692-11697. (https://doi.org/10.1073/pnas.1102715108)

Son DO, Liu W Li X, Prud'homme GJ \& Wang Q 2018 Combined effect of GABA and glucagon-like peptide-1 receptor agonist on cytokineinduced apoptosis in pancreatic beta-cell line and isolated human islets. Journal of Diabetes 11 563-572. (https://doi.org/10.1111/ 1753-0407.12881)

Talchai C, Xuan S, Lin HV, Sussel L \& Accili D 2012 Pancreatic beta cell dedifferentiation as a mechanism of diabetic beta cell failure. Cell $\mathbf{1 5 0}$ 1223-1234. (https://doi.org/10.1016/j.cell.2012.07.029)

Taylor BL, Liu FF \& Sander M 2013 Nkx6.1 is essential for maintaining the functional state of pancreatic beta cells. Cell Reports 4 1262-1275. (https://doi.org/10.1016/j.celrep.2013.08.010)

Tian L, Gao J, Weng G, Yi H, Tian B, O'brien TD \& Guo Z 2011 Comparison of exendin- 4 on beta-cell replication in mouse and human islet grafts. Transplant International 24 856-864. (https://doi. org/10.1111/j.1432-2277.2011.01275.x)

Tian J, Dang H, Chen Z, Guan A, Jin Y, Atkinson MA \& Kaufman DL 2013 Gamma-aminobutyric acid regulates both the survival and replication of human beta-cells. Diabetes 62 3760-3765. (https://doi.org/10.2337/ db13-0931)

Tomas E \& Habener JF 2010 Insulin-like actions of glucagon-like peptide-1: a dual receptor hypothesis. Trends in Endocrinology and Metabolism 21 59-67. (https://doi.org/10.1016/ j.tem.2009.11.007)

Tomas E, Stanojevic V, Mcmanus K, Khatri A, Everill P, Bachovchin WW \& Habener JF 2015 GLP-1(32-36)amide pentapeptide increases basal energy expenditure and inhibits weight gain in obese mice. Diabetes 64 2409-2419. (https://doi.org/10.2337/db14-1708)

Wan Y, Wang Q \& Prud'homme GJ 2015 GABAergic system in the endocrine pancreas: a new target for diabetes treatment. Diabetes, Metabolic Syndrome and Obesity: Targets and Therapy 8 79-87. (https:// doi.org/10.2147/DMSO.S50642)

Wang Q \& Brubaker PL 2002 Glucagon-like peptide-1 treatment delays the onset of diabetes in 8 week-old db/db mice. Diabetologia 45 1263-1273. (https://doi.org/10.1007/s00125-002-0828-3)

Wang Y, Qi M, Mcgarrigle JJ, Rady B, Davis ME, Vaca P \& Oberholzer J 2013 Use of glucagon-like peptide-1 agonists to improve islet graft performance. Current Diabetes Reports 13 723-732. (https://doi. org/10.1007/s11892-013-0402-z) https://joe.bioscientifica.com https://doi.org/10.1530/JOE-20-0315 (c) 2021 Society for Endocrinology Published by Bioscientifica Ltd. Printed in Great Britain 
Wang Q, Ren L, Wan Y \& Prud'homme GJ 2019 GABAergic regulation of pancreatic islet cells: physiology and antidiabetic effects. Journal of Cellular Physiology 2019 1-13. (https://doi.org/10.1002/ jcp.28214)

Weinberg N, Ouziel-Yahalom L, Knoller S, Efrat S \& Dor Y 2007 Lineage tracing evidence for in vitro dedifferentiation but rare proliferation of mouse pancreatic beta-cells. Diabetes 56 1299-1304. (https://doi. org/10.2337/db06-1654)

Wood JR, Miller KM, Maahs DM, Beck RW, Dimeglio LA, Libman IM, Quinn M, Tamborlane WV, Woerner SE \& Network TDEC 2013 Most youth with type 1 diabetes in the T1D Exchange Clinic Registry do not meet American Diabetes Association or International Society for
Pediatric and Adolescent Diabetes clinical guidelines. Diabetes Care 36 2035-2037. (https://doi.org/10.2337/dc12-1959)

Xu E, Kumar M, Zhang Y, Ju W, Obata T, Zhang N, Liu S, Wendt A, Deng S, Ebina Y, et al. 2006 Intra-islet insulin suppresses glucagon release via GABA-GABAA receptor system. Cell Metabolism 3 47-58. (https://doi.org/10.1016/j.cmet.2005.11.015)

Zhao Y, Yang L, Xiang Y, Liu L, Huang G, Long Z, Li X, Leslie RD, Wang X \& Zhou Z 2014 Dipeptidyl peptidase 4 inhibitor sitagliptin maintains beta-cell function in patients with recent-onset latent autoimmune diabetes in adults: one year prospective study. Journal of Clinical Endocrinology and Metabolism 99 E876-E880. (https://doi.org/10.1210/ jc.2013-3633)

Received in final form 21 September 2020

Accepted 25 November 2020

Accepted Manuscript published online 2 December 2020 (c) 2021 Society for Endocrinology Published by Bioscientifica Ltd.
Printed in Great Britain 